\section{El jardín de los senderos que se bifurcan} The garden of forking paths

\section{Sr. Editor:}

He leído con sumo interés el artículo de los Dres. Payá y Domic sobre la enfermedad y muerte de Charles Darwin. A pesar de concluir con una pregunta: " ¿Sería entonces correcto afirmar que Darwin estaba afectado en forma crónica de la enfermedad de Chagas, patología que finalmente lo llevaría a la muerte?"1, la misma tiene más de retórica que de hipotética.

Los autores enfatizan los encuentros de Darwin con la vinchuca ("Benchuca"), describen los síntomas fugazmente, clasificándolos como cardíacos y gastrointestinales y citan a dos de los reconocidos defensores de la teoría chagásica como explicación de la enfermedad y muerte de Charles Darwin, me refiero a los doctores Saúl Adler ${ }^{2}$ y Ralph Bernstein ${ }^{3}$.

Saúl Adler fue un reconocido parasitólogo, con amplia experiencia en malaria (viajó a Sierra Leona en 1921) y en leishmaniasis (escribió un libro sobre sus formas de transmisión Sand Flies to Man). Su apasionamiento por el Darwinismo y su vasta experiencia en el terreno de la parasitología, lo llevaron a publicar una serie de artículos donde adjudicaba al Mal de Chagas la razón de la enfermedad y muerte de Darwin. Sin embargo, el único dato objetivo que liga a Darwin con la enfermedad de Chagas, es una nota en su libro de viajes (HMS Beagle) en 1835, en la que menciona haber sido picado por una vinchuca.

A partir de ese dato, Saúl Adler primero, y más de 20 años después, David Adler sostienen que los síntomas descritos durante la última fase del viaje corresponden a la infección aguda del Mal de Chagas, a la que sigue una fase de latencia extremadamente corta, de menos de 5 años (usualmente la fase de latencia dura entre 15 ó 20 años), y que los síntomas descritos por Darwin, tanto a sus médicos como a sus familiares, corresponden a la fase orgánica de la enfermedad.

Sin embargo, Saúl Adler no pudo acomodar los síntomas presentados por Charles Darwin a una forma específica de la enfermedad. Tampoco pudo explicar, en forma fehaciente, por qué los últimos 10 años de la vida del afamado naturalista inglés fueron los mejores en cuanto a la calidad y estabilidad de su salud. Asimismo, le fue imposible justificar cómo se explica que, siendo afectado por una enfermedad orgánica tan debilitante como el Chagas, Darwin pudiera mantener una carrera intelectual prolífica.

En 1989, David Adler escribe una encendida defensa de la teoría chagásica. Sin embargo, poco aporta al entendimiento, dilucidación y comprensión de qué tipo o variedad de enfermedad chagásica padecía Darwin. En su comentario final, a mi entender, empiezan a develarse algunos de los misterios del por qué, David Adler defiende a capa y espada esta postura:
"La fascinación de Saúl Adler por Darwin y el Darwinismo, y su especial capacidad en el terreno de las enfermedades parasitarias, lo llevaron a sugerir esta alternativa posición para explicar la enfermedad de Darwin".

No hay peor tentación para un investigador que dejarse llevar por la pasión a la hora de establecer una relación de causalidad, menos aún cuando sólo la valoración histórica permitirá develar el misterio y, aún así, con altísima chance de permanecer indescifrable.

Las comparaciones que establece el Dr. Bernstein ${ }^{3}$, entre el caso de Darwin y el de Berenice (la primera paciente en la que se describió el Mal de Chagas), demuestran la falta de comprensión global de la enfermedad chagásica. El Dr. Bernstein confunde el estado de portador asintomático, en caso de que el Dr. Adler estuviera en lo cierto, con una más que prolongada fase de enfermedad orgánica, fuese cardíaca o digestiva.

Las formas digestivas puras en el sur de la Argentina son infrecuentes, mientras que las cardíacas son más prevalentes. Si se tratara de una cardiomiopatía chagásica, sería esperable que luego de 30 ó 40 años existiera algún signo físico de insuficiencia cardíaca. David Adler justifica la ausencia de dichos síntomas, aduciendo que se trató de formas solapadas de la enfermedad, lo cual entonces no justifica los posibles signos y síntomas cardíacos.

Vieira ${ }^{5}$, un clínico brasilero, avala la clasificación de síntomas experimentados por Darwin, propuesta en 1963 por Kohn ${ }^{6}$ en: digestivos (náuseas y vómitos, pero ausencia de disfagia y constipación), cardíacos (palpitaciones y dolor de pecho pero sin síntomas atribuibles a insuficiencia cardíaca) y nerviosos (fatiga, cansancio, insomnio, temblores, cefalea, etc). Propone denominar como forma neuro-psíquica del Mal de Chagas a esta forma que se presenta con múltiples y vagos síntomas y sin enfermedad orgánica manifiesta. Basado en el trabajo original de Adler, Vieira sostiene que la enfermedad de Chagas es más probable de ser el causante de los síntomas, que cualquier otra de las alternativas diagnosticas.

Esta variedad de enfermedad chagásica no es considerada en la actualidad, pero el conocimiento en el terreno de la dis-autonomia chagásica durante el período latente de la enfermedad, ha sido profundamente explorado y analizado.

Creo importante señalar aquí el resto de las alternativas diagnósticas que se han considerado en la literatura:

- enfermedad psicosomática ${ }^{7,8}$ se basa fundamentalmente en la variedad y diversidad de síntomas, en la falta de signos, en los "gatillos" que empeoraban la condición de Darwin -siempre relacionados a situaciones de alto estrés como la presentación de abstracts, ponencia ante sus pares, etc.

- astigmatismo ${ }^{9}$ a pesar de nunca haber sido retrata- 
do con anteojos, Gould un conocido oftalmólogo de principio de siglo, concluye que una combinación de astigmatismo y presbiopía podrían justificar la mayoría de los síntomas

- brucelosis, en la década del '50, el Dr. Simpson ${ }^{10}$ intentó justificar, sin éxito, toda la constelación de síntomas bajo esta entidad prevalente en el sur de Argentina:

- migraña

- epilepsia

- arsenismo

- hipoglucemia

- encefalomielitis

- múltiples alergias

- narcolepsia...

y la lista sigue, incluyendo algunos diagnósticos claramente improbables.

Posiblemente, el trabajo que más desarticula la teoría chagásica, es el del Dr. Woodruff en $1968^{11}$. Además de las ya mencionadas contradicciones de la teoría chagásica, Woodruff demuestra como la constelación de síntomas que afectaban al creador de la teoría evolutiva, eran también comunes en sus predecesores y descendientes, tornando la teoría chagásica aún menos probable.

Por su parte, los Drs Castagnino y Thompson ${ }^{12}$ también descreen de la teoría chagásica y aportan un elemento importante en la discusión: ¿Cuál pudiera ser la motivación para sostener la enfermedad chagásica o cualquier otra teoría en forma tan enfática?

La respuesta a esta pregunta no es sencilla y permanecerá, de alguna manera, especulativa.

El primer componente es el apasionamiento por explicar un determinado fenómeno, desde nuestra área de entendimiento. Esto se potencia ante la certeza de que una falta de respuesta categórica pudiera aniquilar nuestra hipótesis. Este apasionamiento puede llevarnos a concluir erróneamente, que nuestras presunciones son verdaderas, aun ante la falta de evidencia.

El segundo componente es de carácter políticosocial. En la era actual, desacreditar el pensamiento en función de aspectos personales (enfermedades, adicciones, preferencias sexuales o políticas), todavía constituye una herramienta de ataque usada con frecuencia.

En forma sencilla, debajo de este andamiaje especulativo en torno a la enfermedad de Darwin podría ocultarse un razonamiento del tipo "cómo este hombre va a explicarnos a nosotros la evolución del hombre, cuando no pudo siquiera combatir a un pequeño insecto".

Intentando contestar entonces la pregunta inicial de los Drs Payá y Domic diría que no se puede afirmar que Charles Darwin padecía una forma crónica de enfermedad de Chagas. Hay poca, o casi nula, evidencia para afirmarlo y una total imposibilidad para probarlo.
Podría quedar, respetando los pasos de los investigadores que nos precedieron, como una alternativa diagnóstica pero poco probable a los ojos de quien escribe, sin apasionamiento alguno, esta nota.

\section{Referencias}

1.- Payá G E, Domic T D. The misterious disease that affected Charles Darwin. Rev Chil Infectol 2008; 25: 207.

2.- Adler S. Darwin's illness. Nature 1959; 184: 1102-4.

3.- Bernstein R. Darwin's illness: Chagas' disease resurgens. J R Soc Med 1984; 77: 608-9.

4.- Adler D. Darwin's illness. Israel J Med 1989; 25: 218 21.

5.- Vieira C B. Theory about Darwin having Chagas disease? Rev Bras Med 1967; 24: 782-4.

6.- Kohn L A. Charles Darwin's chronic ill health. Bull Hist Med 1963; 37: 239-56.

7.- Padis N. On the health of Charles Darwin. Trans Stud Coll Physicians Phila 1973; 41: 31-4.

8.- Alvarez W C. The nature of Charles Darwin's life-long ill-health. New Engl J Med 1959; 261: 1109-12.

9.- Gould G M. Biographic Clinics. Philadelphia: Blakiston, 1902, vol 1, p. 89.

10.- Simpson G G. Sci Am 1958; 199: 121.

11.- Woodruff A W. The impact of Darwin's voyage to South America on his work and health. Bull N Y Acad Med 1968; 44: 661-72.

12.- Castagnino H E, Thompson A C. ¿Sufrio Darwin la enfermedad de Chagas? Medicina (B Aires) 1981; 41: 263-4.

\author{
Adrian Baranchuk \\ Kingston General Hospital, \\ Ontario, Canadá \\ barancha@kgh.kari.net
}

\section{Respuesta}

Estimado Editor:

$\mathrm{Me}$ es grato saber que nuestra modesta contribución haya motivado el interés de lectores tan distantes como el Dr. Adrian Baranchuk, de la ciudad de Ontario.

En su carta, se extiende en las numerosas, y posiblemente válidas teorías respecto de la aún "misteriosa enfermedad de Charles Darwin", cosa que no podíamos hacer en el artículo original; lo más probable es que la incógnita persista por mucho tiempo debido, entre otras cosas, a la negativa de la Abadía de Westminster, donde se encuentra sepultado Darwin, de permitir el análisis de sus restos.

Atentamente,

Ernesto Payá G. 